\title{
RIFTEAMENTOS SUPERPOSTOS E TECTÔNICA DE INVERSÃO NA BORDA SUDESTE DO CRÁTON DO SÃO FRANCISCO
}

\author{
Alexandre Uhlein (*), Roland Trompette $(* *)$ \\ \& Marcos Egydio-Silva (***)
}

\begin{abstract}
This paper presents a stratigraphical and structural study of the transition zone between São Francisco Craton and Araçuaí Fold Belt in the Minas Gerais state. Two extensional events with rift formation and sedimentation and one orogenic event can be studied.

The first extensional event was dated at 1750-1700 Ma. This event is represented by the N-S Espinhaço basin formation in a continental rift. Its lower part (Early Sequence) is made of acid to intermediate metavolcanics and fluvial metasediments, with strong fault-block activity in an initial rift phase (mechanical subsidence). The Middle Sequence is composed by quartzite with big cross-bedding and the Upper Sequence consists of an alternation of quartzite and metapelitic rocks deposited in a shallow marine setting in a subsequent flexural phase (with termal subsidence).

The second extensional phase corresponded to Araçuaí rift formation (1000-900 Ma), with mafic dikes swarm in the Espinhaço Supergroup. On the highest uplifted continental glaciogenic facies and glacio-marine sequence (Jequitaí Formation) was deposited. To east, in the Araçuaí basin, they grade into marine deposits with gravitational sedimentation (debris-flow and turbidites) in a typical prism of passive continental margin. Westward, on the craton, the Bambuí Group lies directly on the basement. No equivalents have been identified in the Araçuaí basin either they have not been deposited or are eroded.

The orogenic event $(650-550 \mathrm{Ma})$ is caracterized by zones with asymetric folds showing westwards vergence separated by thin belts of ductile shearing ( Dp phase). N-S Sp cleavage with stretching lineation to east indicates a westward transport of materials toward the São Francisco Craton. The regional Barrowian metamorphism is associated to $\mathrm{Dp}$, increasing from anchizone to amphibolite facies. During this orogenic event the São Francisco Craton and the Araçuaí and Paramirim Fold Belts were formed as individual geotectonics units.
\end{abstract}

\section{ARCABOUÇO GEOLÓGICO REGIONAL}

A estrutura geológica do Brasil é, em grande parte, herdada da orogênese brasiliana, evento tectônico que ocorreu no final do Pré-Cambriano (650-550 m.a.). Os crátons, poupados por este evento, foram separados por uma rede de faixas de dobramentos brasilianos. A área abrangida por este trabalho compreende a borda sudeste do Cráton do São Francisco e a porção externa da Faixa Araçuaí (Almeida 1977), no Estado de Minas Gerais (Fig. 1).

A unidade estrutural do Cráton do São Francisco é constituída, estratigraficamente, pelo embasamento de idade arqueana/paleoproterozóica, não remobilizado, da região de Belo Horizonte; pelo Supergrupo Espinhaço da região da Serra do Cabral; e pela Formação Jequitaí e pelo Grupo Bambuí, estes dois últimos geralmente inclusos no Supergrupo São Francisco. Esta unidade estrutural apresenta camadas horizontais a oeste, anquimetamórficas, que, progressivamente para leste, tornam-se dobradas e afetadas por zonas de cisalhamento dúcteis-rúpteis com vergência para oeste e metamorfismo da fácies xisto verde (Chang et al. 1988; Marshak \& Alkmim 1989; Uhlein 1991; Alkmim et al. 1993). Deve-se distinguir na unidade cratônica um domínio de cobertura cratônica sensu strictu ( horizontal ) e um domínio de cobertura deformada, dobrada, com presença de xistosidade e lineação de estiramento.

A Faixa de Dobramentos Araçuaí pode ser subdividida em dois domínios estruturais (Uhlein \& Trompette 1993). O domínio externo é caracterizado por um metamorfismo da fácies xisto verde a anfibolito e apresenta uma sucessão de zonas com dobras assimétricas com vergência para oeste, separadas por zonas de cisalhamento dúctil-rúptil, que mostram uma estrutura homoclinal. Esta deformação manifesta-se por uma xistosidade $\mathrm{Sp}$, orientada norte-sul; 20 a $50^{\circ}$ este e uma lineação de estiramento proeminente orientada segundo este; 20 a $50^{\circ}$, e que indica a direção de transporte tectônico. A unidade externa da Faixa Araçuaí é constituída pelo embasamento remobilizado pela orogênese brasiliana (Anticlinórios de Gouveia, Porteirinha e de Guanhães ), o Supergrupo Espinhaço da serra homônima (setor meridional) e o Grupo Macaúbas (incluindo o Complexo ou Unidade Salinas, conforme Pedrosa Soares et al. 1992).

A unidade interna da Faixa Araçuaí constitui o prolongamento norte do Cinturão Atlântico ou da Faixa Ribeira. Esta região não fazia parte da Faixa Araçuaí na concepção de Almeida (1977). Os trabalhos geocronológicos de Siga Jr. (1986) e Siga Jr. et al. 
(1987) mostraram que estes terrenos devem corresponder a material brasiliano altamente metamórfico. Esta região, ao contrário da unidade externa, não possui vergência bem definida. É constituída pelo Complexo Jequitinhonha (Almeida \& Litwinski 1984), que apresenta gnaisses kinzigíticos, quartzitos, xistos, calcissilicáticas e inúmeras intrusões de granitóides leucocráticos, que mostram contatos, em parte transicionais com os gnaisses. Núcleos de embasamento intensamente remobilizados poderiam ser identificados com o aumento das pesquisas.

A Serra do Espinhaço Meridional (locus do Supergrupo Espinhaço) está inserida na unidade externa da Faixa Araçuaí. Seu prolongamento norte, para dentro do Cráton do São Francisco é motivo de recente polêmica. Alguns acreditam que a deformação do $\mathrm{Sg}$.
Espinhaço nesta região é do Mesoproterozóico (Jardim de Sá et al. 1976; Brito Neves et al. 1979; Cordani et al. 1992), enquanto que outros acreditam que a deformação seja do Neoproterozóico (Trompette et al. 1992; Chemale Jr. et al. 1993; Schobbenhaus 1993). Considerando que a deformação nesta região está ligada ao Ciclo Brasiliano, Trompette et al. (1992) definiram a faixa de dobramentos Paramirim, que representa um prolongamento intracontinental da Faixa Araçuaí, dividindo em dois o antigo Cráton do São Francisco, conforme a concepção de Almeida (1977) (Fig.1). A leste da Faixa Paramirim aflora o domínio cratônico (Cráton de Salvador-Oeste do Congo) com embasamento não remobilizado e coberturas do Proterozóico Médio (Sg. Espinhaço) e do Proterozóico Superior (Fm. Bebedouro e Gr. Una, ambas incluídas no Sg São Francisco).

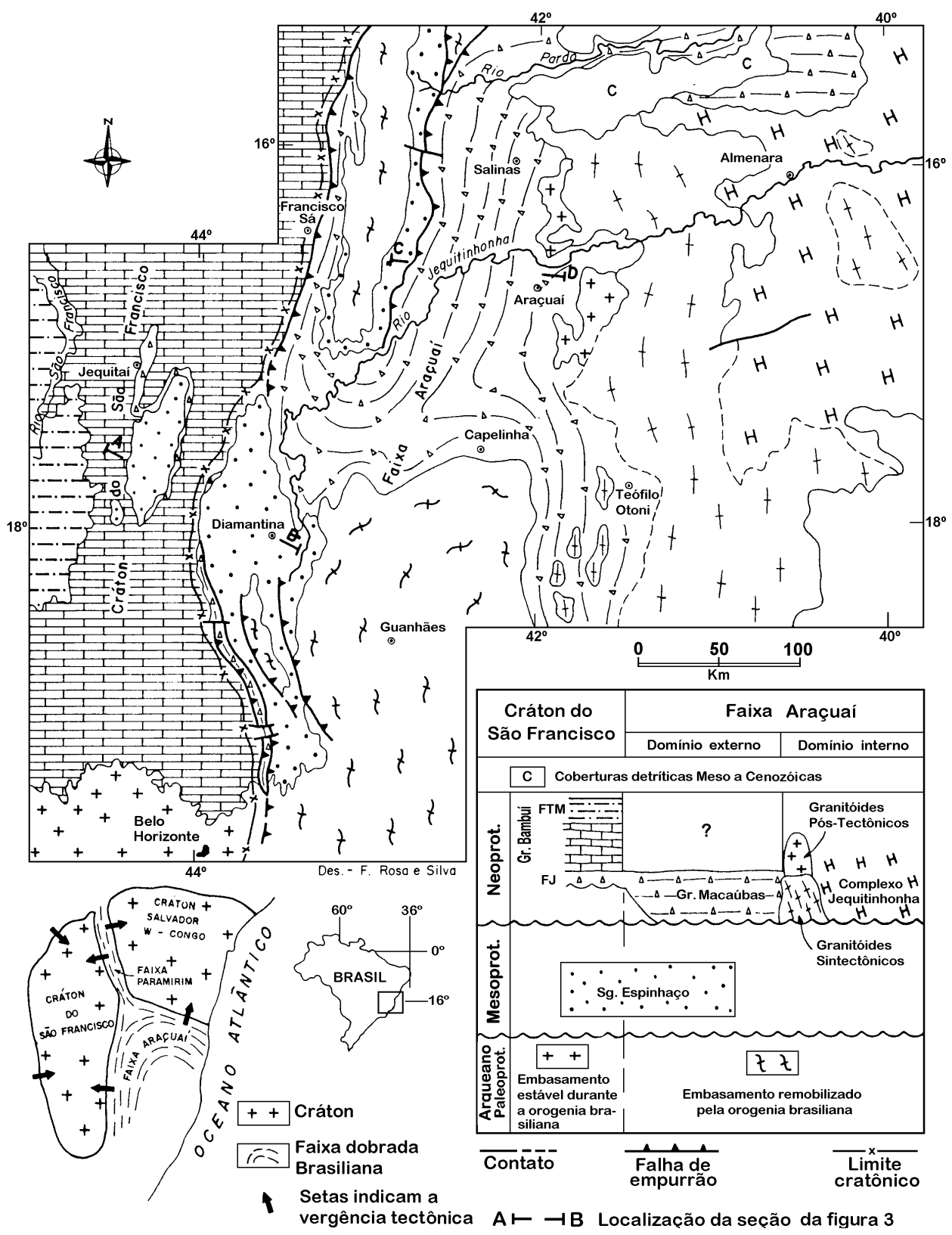

Figura 1: Subdivisão tectono-estratigráfica da borda SE do Cráton do São Francisco e Faixa Araçuaí (Modificado de Schobbenhaus et al. 1981).

Figure 1: Tectono-stratigraphic division of the SE border of the São Francisco Craton and the Araçuai fold belt (modified after Schobbenhaus et al. 1981). 
Os limites geocronológicos utilizados neste trabalho são os sugeridos por Fuck (1991), conforme a IUGS, assim relacionados: Arqueano (>3,6-2,5 b.a.), Paleoproterozóico (2,5-1,6), Mesoproterozóico (1,61,0) e Neoproterozóico (1,0-0,5 b.a.) .

\section{RIFTEAMENTO DO FINAL DO PALEOPROTEROZÓICO E INÍCIO DO MESOPROTEROZÓICO : SUPERGRUPO ESPINHAÇO.}

O Supergrupo Espinhaço foi depositado num rifte continental submeridiano. Foi preenchido por rochas siliciclásticas, contendo raras rochas vulcânicas e carbonáticas (Pflug, 1965 1968; Schöll \& Fogaça 1979; Garcia \& Uhlein 1987; Dossin et al.1990 ).

Na região de Mato Verde, norte de Minas Gerais, ocorre, na base do Supergrupo Espinhaço, um importante vulcanismo ácido-intermediário subalcalino (riolitos, riodacitos, traquitos pouco metamórficos) com intercalações de rochas metapiroclásticas e metassedimentares (quartzitos e metaconglomerados), conforme Menezes Filho (1981). Um metatraquito desta unidade foi datado pelo método $\mathrm{U} / \mathrm{Pb}$ em zircão, indicando idade aproximada de 1750 m.a.(M.Babinski, informação verbal). Este vulcanismo é sincrônico aos metariolitos de Conceição do Mato Dentro que, através do método $\mathrm{U} / \mathrm{Pb}$ em zircão, indicaram idades de 1770 e 1710 m.a. (Brito Neves et al. 1979; Machado et al.,1989). É importante, ainda, destacar a intrusão do granito subalcalino Borrachudos, a sudeste da Serra do Espinhaço Meridional, cuja datação geocronológica U/ $\mathrm{Pb}$ em zircão indicou idade de 1730 m.a.(Dossin et al.,1993a). Este vulcanismo e plutonismo subalcalino está relacionado à individualização do rifte Espinhaço, num contexto de extensão intraplaca e anatexia crustal localizada ( Jardim de Sá et al. 1976; Costa \& Inda 1982; Uhlein,1991; Schobbenhaus 1993; Dussin, I. A. 1994; Dussin, T. M. 1994).

A porção basal (Sequência Inferior) do Supergrupo Espinhaço é constituída pelas Formações São João da Chapada e Sopa-Brumadinho (100 a 700 metros de espessura) que mostram, predominantemente, quartzitos de granulometria variada, ricos em estratificações cruzadas, com níveis de metapelitos e metaconglomerados lenticulares (Schöll \& Fogaça 1979). Esta unidade foi depositada em ambiente continental, com fácies de leque aluvial, fluvial braided, fandelta e, localmente, sistema marinho raso (Garcia \& Uhlein 1987; Martins Neto et al. 1988; Uhlein 1991; Martins Neto 1993; Fleischer 1993). Almeida Abreu (1993) descreveu sedimentos lacustres na Formação Sopa-Brumadinho, semelhante aos riftes cenozóicos do Leste da África. A morfologia da bacia é de meio gráben ou gráben assimétrico, cujo embasamento mergulhava progressivamente para leste. Atividade tectônica sinsedimentar ocorreu na forma de falhas normais aproximadamente norte-sul, gerando horst e grabens secundários. Falhas transferentes com orientação E-W podem ter ocorrido, permitindo acomodação da deformação extensional. A sedimentação foi influenciada pelo tectonismo sinsedimentar, com rápidas e frequentes variações faciológicas. O vulcanismo foi localizado, na forma de diques e sills de xisto verde (provavelmente metabasaltos e metatufos básicos, conforme Renger 1970 e Hoppe \& Otto 1982) e hematita filitos, de origem controvertida, provavelmente vulcanitos de filiação alcalina, altamente potássicos, com alteração pósdeposicional importante, provavelmente metamórfica (Dussin, T. M. 1994) ou intempérica, durante o Proterozóico (Knauer 1990; Knauer \& Schrank 1994). O filito hematítico foi datado por $\mathrm{Pb} / \mathrm{Pb}$ em monozircão, indicando idade de $1710 \mathrm{~m}$.a. (Dossin et al. 1993a), que deve representar a idade de sedimentação da porção basal do Sg. Espinhaço.

Almeida Abreu (1993) e Silva (1993) sugeriram incluir a Formação Bandeirinha na base do Sg. Espinhaço. Esta unidade aflora localmente, entre Diamantina e Gouveia e foi descrita, originalmente, como pertencente ao Sg. Rio Paraúna, unidade supracrustal arqueana (Fogaça et al. 1984). As semelhanças petrográficas e sedimentológicas com o $\mathrm{Sg}$. Espinhaço levaram aqueles autores a proporem esta nova unidade.

A Formação Galho do Miguel (Sequência Média) é constituída por quartzitos finos, com elevado grau de maturidade e apresenta, às vezes, estratificações cruzadas gigantes, indicando o registro de depósitos eólicos costeiros (Dossin et al. 1987; Garcia \& Uhlein 1987). Foi depositada em condições de quiescência tectônica em relação as precedentes e com alargamento do sítio deposicional. Estes aspectos sugerem que sua deposição ocorreu numa fase de subsidência térmica e flexural (Uhlein 1991; Martins Neto 1993; Almeida Abreu 1993; Schobbenhaus, 1993), posterior a fase principal do rifteamento.

O Grupo Conselheiro Mata (ou Sequência Superior) possui espessura em torno de 800 metros, sendo subdividido em diversas formações que representam alternâncias de metassiltitos e/ou metapelitos com quartzitos, geralmente finos a médios e bem selecionados (Pflug 1968; Schöll \& Fogaça 1979). As unidades estratigráficas representam ciclos transgressivos e regressivos de sistemas deposicionais marinho raso, com influência de ondas e marés ( Garcia \& Uhlein 1987). As formações são extensas e regulares, indicando estabilidade tectônica na bacia, em fase de subsidência térmica e flexural (Chang et al. 1989; Uhlein 1991). No topo, afloram quartzitos conglomeráticos de origem fluvial que representam um evento regressivo importante, provavelmente um prenúncio do evento glacial Jequitaí.

A existência de embasamento gnáissico nos dois lados da Serra do Espinhaço, a importância da tectônica extensional na base da unidade, a natureza da sedimentação (continental e marinho raso), a natureza do vulcanismo e plutonismo ácido subalcalino, indicam que a estrutura do Sg. Espinhaço é um rift intracontinental ou ensiálico (Jardim de Sá et al. 1976; 
Costa \& Inda 1982; Uhlein 1991; Schobbenhaus 1993). Herrgessel (1985), Herrgesell \& Pflug (1986), Almeida Abreu (1993) e Almeida Abreu \& Pflug (1994) interpretaram o Sg. Espinhaço em Minas Gerais, como uma margem continental passiva. A inexistência de sedimentos de água profunda (sedimentação gravitacional) espessos e a dificuldade em caracterizar um evento tectono-metamórfico responsável pelo fechamento ou inversão da margem passiva (orogênese) no final do Mesoproterozóico, inviabilizam o referido modelo. Com os atuais dados existentes parece mais factível um modelo de rifte ensiálico do Mesoproterozóico tectonizado na orogênese brasiliana (Trompette et al. 1992; Chemale Jr. et al 1993; Schobbenhaus 1993; Alkmim et al. 1993; Dussin, I.A. 1994; Dussin, T. M. 1994).

A borda leste da Serra do Espinhaço Meridional tem sido motivo de grandes controvérsias. Nesta região, Pflug (1965) propôs uma interdigitação entre quartzitos e itabiritos, associados a rochas meta-ultrabásicas e gnaisses, produto de uma evolução geossinclinal da Série Minas. Desde então, diversos trabalhos foram realizados nesta região, procurando detalhar a geologia (veja síntese em Renger,1995). No início da década de 80, foi caracterizado, pela primeira vez, um sistema de falhas inversas ou de empurrão que invertiam as unidades estratigráficas da região (Assis \& Marini 1983; Uhlein \& Dardenne 1984; Herrgesell \& Pflug 1986; Almeida Abreu et al. 1986). Atualmente, os gnaisses são considerados como pertencentes ao embasamento arqueano da região (como consequência de estudos geocronológicos, p.ex. Brito Neves et al. 1979) e as rochas meta-ultrabásicas são atualmente interpretadas como sequências vulcano-sedimentares (greenstone belts), provavelmente arqueanas (Uhlein 1982; Uhlein et al.,1983; Hergessell,1985). Os itabiritos estão encaixados em sequências de quartzitos e filitos e são correlacionáveis ao Supergrupo Minas, da região do Quadrilátero Ferrífero (Assis \& Marini 1983; Dossin 1985), com evolução tectono-metamórfica associada ao Ciclo Transamazônico e reativação no Ciclo Brasiliano (Dossin \& Charvet,1993; Dussin, I.A. 1994). Os quartzitos, atualmente pertencentes ao Sg. Espinhaço, foram depositados no Mesoproterozóico e sofreram apenas o evento tectono-metamórfico do Ciclo Brasiliano (Uhlein et al. 1986).

Entretanto, Almeida Abreu et al. (1989) e Almeida Abreu \& Pflug (1994) defendem que os itabiritos da borda leste da Serra do Espinhaço sejam sedimentos distais da margem passiva do Espinhaço e que as rochas meta-ultrabásicas sejam representantes de uma hipotética crosta oceânica e que evoluiram como ofiolitos mesoproterozóicos.

Assim sendo, diversos trabalhos (p.ex. Uhlein et al. 1983; Assis \& Marini 1983; Dossin 1985; Dossin \& Charvet 1993; Dussin, I. A. 1994) defendem que a borda leste da Serra do Espinhaço é constituída por diversas unidades estratigráficas imbricadas tectonicamente e afetadas por no mínimo dois ciclos orogenéticos (Transamazônico e Brasiliano), enquanto que outros pesquisadores acreditam que as supracrustais pertençam ao $\mathrm{Sg}$. Espinhaço, representando fácies distais, em parte asociadas à crosta oceânica de uma margem passiva e deformadas nos ciclos Uruaçuano e Brasiliano (Renger 1970; 1972; Herrgesell 1985; Herrgesell \& Pflug 1986; Almeida Abreu et al. 1989; Almeida Abreu 1993; Almeida Abreu \& Pflug 1994).

\section{RIFTEAMENTO BRASILIANO E ABERTURA DA BACIA ARAÇUAÍ}

Um tectonismo extensional, provocando um levantamento generalizado e basculamentos localizados no Supergrupo Espinhaço, gera um rifte de grandes proporções na margem sudeste do futuro Cráton do São Francisco. A porção nordeste da Serra do Espinhaço é profundamente erodida. Intrusões de rochas básicas, na forma de gabros e diabásios toleíticos continentais (Uhlein 1991; Silva et al. 1992; Dossin et al. 1993b) entre 1.100 e 1.000 m.a. no sudeste da Bahia (D'Agrella Filho et al. 1990) e 906 m.a. (U/Pb em zircão - Machado et al. 1989 - na Serra do Espinhaço) acompanham o tectonismo extensional e parecem associadas à formação de um sistema de riftes do Gondwana Ocidental (Trompette 1994). Altas taxas de extensão devem ter ocorrido, levando à formação localizada de crosta oceânica (Pedrosa Soares et al. 1990; Uhlein 1991; Pedrosa Soares et al. 1992; 1993). Uma glaciação (Karfunkel e Hoppe 1988) ocorreu no âmbito do futuro Cráton do São Francisco, em parte associada ao relevo positivo da margem do rifte. O preenchimento sedimentar deste rifte está relacionado a duas sequências: inferior e superior (Fig. 2).

\section{Sequência Inferior}

A Formação Jequitaí e o Grupo Macaúbas compreendem o material sedimentar que preencheu o rifte brasiliano, provavelmente durante o período de 900 a 700 m.a.

A Formação Jequitaí repousa em discordância sobre o Supergrupo Espinhaço, na região cratônica da Serra do Cabral e é sobreposta pelo Grupo Bambuí. É constituída dominantemente por diamictitos maciços e estratificados com matriz areno-argilosa e seixos, blocos e grânulos dispersos de gnaisse, granitos, quartzitos, metassiltitos e calcários. Localmente mostram intercalações lenticulares de metarenitos e metaritmitos. A espessura varia de 0 a 100 metros. Análise de fácies e processos deposicionais não identificou tilitos sensu strictu, mas sedimentos glaciomarinhos depositados em plataforma marinha rasa relacionados a fluxos gravitacionais glaciogênicos formados pelo recuo e degelo glacial, preenchendo bacias tectônicas (grábens), ou mesmo controlados pela paleotopografia.

O Grupo Macaúbas consiste no equivalente geossinclinal da Formação Jequitaí, com maior espessura devido a maior subsidência da bacia Araçuaí 


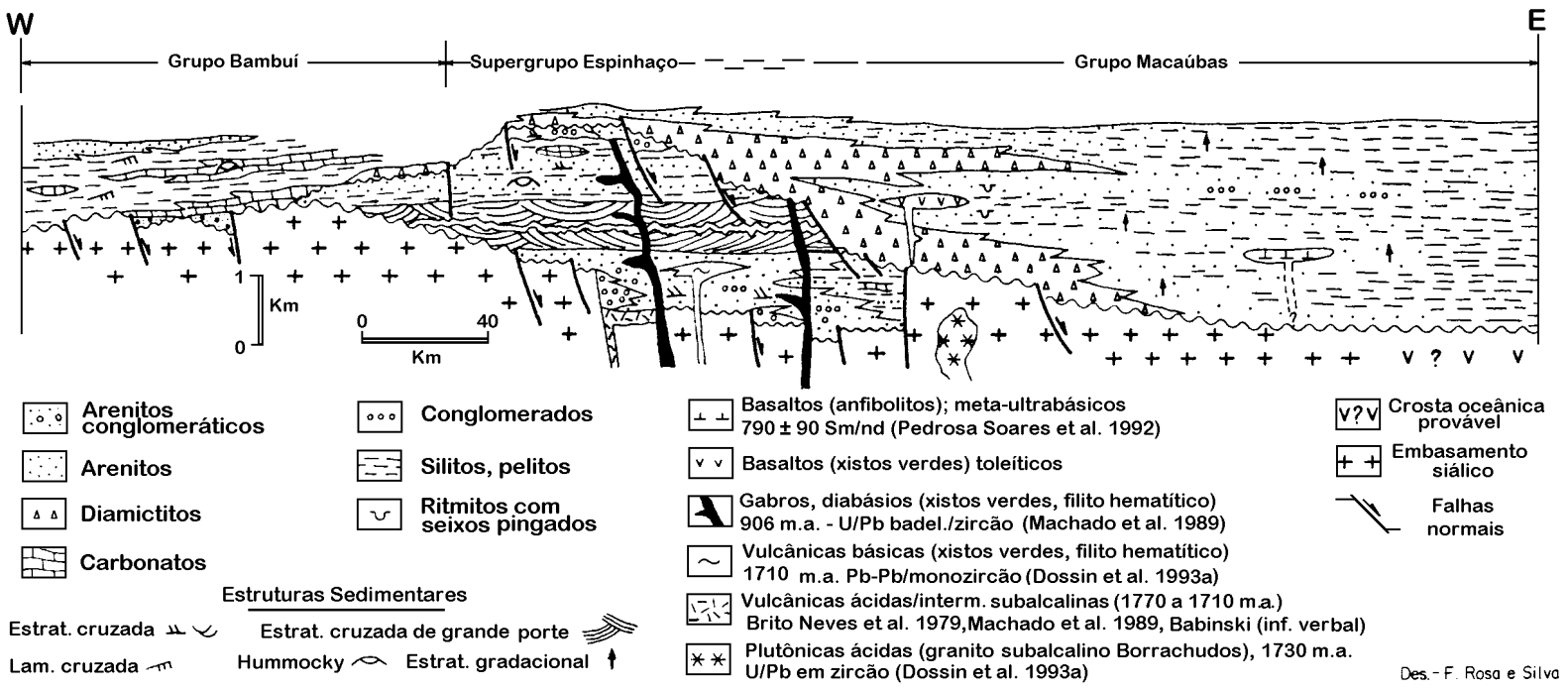

Figura 2: Quadro estratigráfico na borda sudeste do Cráton do São Francisco (modificado de Uhlein, 1991). Figure 2: Stratigraphic synopsis of the SE border of the São Francisco Craton (modified from Uhlein, 1991).

(Karfunkel \& Karfunkel 1976; Uhlein 1991). O Grupo Macaúbas tem espessura de alguns quilômetros e consiste de metadiamictitos que passam lateral e verticalmente para metaritmitos (quartzitos, metapelitos). Os diamictitos possuem matriz arenoargilosa e grânulos, seixos e matacões de quartzitos, granitóides, calcários, xistos e quartzo, apresentando algumas intercalações de metaconglomerados, quartzitos e metaritmitos. As fácies de metaritmitos são constituídas por quartzitos e metapelitos em diversos arranjos de espessura, às vezes mostrando estratificações gradacionais e demais intervalos da sequência de Bouma e, ainda, seixos pingados (dropstones), especialmente na porção sul da bacia. $\mathrm{O}$ Grupo Macaúbas consiste de material glacial ressedimentado e depositado como debris-flow subaquoso e por correntes de turbidez (metaritmitos turbidíticos). No Grupo Macaúbas pode-se distinguir, estratigraficamente, duas sequências de diamictitos que, lateral e verticalmente, passam a duas sequências turbidíticas, cuja granulometria decresce para leste.

Uhlein et al. (1994) apresentaram um modelo deposicional para a sequência Jequitaí - Macaúbas, onde haveria uma transição entre uma plataforma marinha glaciada ( Formação Jequitaí ) e a borda de uma bacia extensional, formada por falhas normais aproximadamente N-S (rifte da bacia Araçuaí), onde o material glaciogênico inconsolidado e o embasamento são retrabalhados por fluxos gravitacionais sub-aquosos.

\section{Sequência Superior}

O Grupo Bambuí representa a continuidade da sedimentação da cunha mioclinal, posteriormente a glaciação, com elevação generalizada do nível dos mares (Pflug et al. 1980; Uhlein 1991). Possui depósitos de conglomerados na base, muito localizados, e para o topo, depósitos de plataforma carbonática e ritmitos síltico-argilosos, depositados sobre um embasamento estável, compartimentado por falhas normais (Costa \& Branco 1961; Dardenne 1981), de direção N-S. Para o topo do Grupo Bambuí, aparecem fácies regressivas ( Formação Três Marias) sugerindo que sua sedimentação foi em parte reflexo das fases de compressão da Faixa Araçuaí (Uhlein 1991; Chiavegatto 1993).

Dados geocronológicos indicam idades de sedimentação entre 650 e 600 m.a. ( Parenti Couto et al. 1981 e Macedo \& Bonhome 1984 in Babinski 1993), mas podem ter sido influenciadas pelos efeitos tectonometamórficos do Ciclo Brasiliano. Idade de sedimentação fornecida pelos estromatólitos colunares indicam idades entre 800 e 600 m.a. (Dardenne 1981).

A ampliação da bacia Bambuí, às vezes diretamente em contato com o embasamento (por exemplo na região de Sete Lagoas) não se deve apenas a subida do nível dos mares mas, também, a uma fase de expansão da subsidência na área estável, adjacente ao rifte da bacia Araçuaí. Este episódio de expansão de subsidência pode estar relacionado a uma fase térmica e flexural do rifte Araçuaí ( Domingues 1993), entretanto, não existe registro de sedimentação do Grupo Bambuí dentro do rift Araçuaí. Eventualmente, estes depósitos sedimentares poderiam não ter sido depositados ou, mais provavelmente, foram profundamente erodidos, haja visto a forte tectônica de inversão (orogênese) que estabeleceu-se na bacia Araçuaí e o atual nível de erosão, que expõe rochas de mesozona e catazona na direção do Oceano Atlântico.

Assim sendo, os principais controles da sedimentação pelito-carbonática do Grupo Bambuí foram a elevação do nível dos mares, o clima, a posição paleogeográfica ou latitude e a expansão da subsidência térmica e flexural, quando do final da evolução da Bacia Araçuaí. 


\section{TECTÔNICA DE INVERSÃO (FASE OROGENÉTICA BRASILIANA)}

Esta fase corresponde a orogênese brasiliana que foi responsável pela inversão da bacia Araçuaí, afetou profundamente o sistema Espinhaço e moldou os limites do Cráton do São Francisco (Fig. 3). Almeida (1977) definiu os limites deste cráton como função de falhas significativas, preferencialmente as mais externas das faixas de dobramentos. Recentemente, diversos trabalhos de geologia estrutural foram efetuados nas zonas limítrofes cráton-faixa (veja síntese em Alkmim et al. 1993) e estes trabalhos mostraram que os limites são gradacionais, onde existe a passagem de um cinturão de dobramentos e cavalgamentos, com tectônica de nappes e embasamento envolvido (thick skinned) nas faixas de dobramentos, para um cinturão de ante-país, moldado na cobertura proterozóica deformada do cráton, com estruturas do tipo thin skinned. Estes trabalhos mostraram, também a passagem gradativa entre um domínio cratônico sensu strictu, com camadas subhorizontais e anquimetamórficas, para um domínio de cinturão de antepaís com tectônica epidérmica e metamorfismo da fácies xisto verde.

Litwinski (1985), Siga Jr. et al. (1987), Uhlein et al. (1990), Uhlein (1991) e Pedrosa Soares et al. (1992) descrevem a estrutura da Faixa Araçuaí. Duas fases com evolução progressiva estruturaram a faixa de dobramentos (Fig. 3 e 4 ). A primeira, denominada por Uhlein de Dp-1, está relacionada a uma xistosidade Sp-1 que ocorre em micrólitons da xistosidade principal (Sp) e está ligada, provavelmente, a movimentos tangenciais, subparalelos ao acamamento, possivelmente incluindo nappes de grande extensão. A segunda fase, denominada de Dp, é a fase mais importante e é caracterizada por uma sucessão de zonas com dobras assimétricas com vergência para oeste, separadas por corredores de cisalhamentos dúcteis ou dúcteis-rúpteis. Esta deformação se manifesta por uma xistosidade (Sp) e uma lineação de estiramento (Lx) proeminente, que indica um transporte de material de este para oeste, em direção ao Cráton do São Francisco. As dobras amplas e assimétricas, localmente de flanco invertido, apresentam eixo norte-sul, vergência para oeste e xistosidade ou clivagem ardosiana Sp de plano axial. As zonas de cisalhamento mostram orientação norte-sul, xistosidade Sp milonítica, forte estiramento do material para leste, principalmente seixos de conglomerados, foliações $\mathrm{S} / \mathrm{C}$ e indicadores cinemáticos para oeste. Localmente observa-se a fase $\mathrm{Dp}+1$, com dobras suaves da xistosidade Sp, formação de clivagem espaçada ou de crenulação plano-axial. A Faixa Araçuaí é caracterizada por uma deformação do tipo cisalhamento simples e a tectogênese brasiliana está relacionada ao intervalo 650-550 m.a.

A Serra do Espinhaço está inserida no domínio externo da Faixa Araçuaí e sua tectogênese está relacionada ao Ciclo Brasiliano (Uhlein et al. 1986; Marshak \& Alkmim 1989; Alkmim et al. 1989; Uhlein et al. 1990; Uhlein 1991; Dossin et al. 1992; Uhlein \& Trompette 1993; Alkmim et al. 1993, Dussin, I. A. 1994; Dussin, T. M. 1994). Ao norte, vários autores chegaram a conclusões semelhantes, como Bertholdo et al. (1993) em Palmas de Monte Alto (BA), Danderfer Filho et al. (1993) na região da Chapada Diamantina e Schobbenhaus (1993) na Serra do Espinhaço Setentrional.

As primeiras estruturas formadas pela tectônica de inversão do Ciclo Brasiliano na Serra do Espinhaço foram zonas de cisalhamento paralelas ao acamamento (So), o qual mostrou-se mecanicamente ativo, acomodando a deformação inicial e permitindo a geração da xistosidade $\mathrm{Sp}-1$. Em seguida desenvolveram-se megadobramentos, associados a uma clivagem ou xistosidade plano-axial (denominada de $\mathrm{Sp}$ ), com orientação norte-sul e mergulho íngreme para leste, desenvolvidos por mecanismos de deslizamento flexural. São dobras geralmente assimétricas, de eixo norte-sul, indicando transporte tectônico para oeste. Lineações minerais (sericita,cianita) associam-se às duas xistosidades, especialmente à $\mathrm{Sp}$, orientadas para leste. Finalmente falhas inversas ou de empurrão, orientadas norte-sul, mostram geometria em duplexes

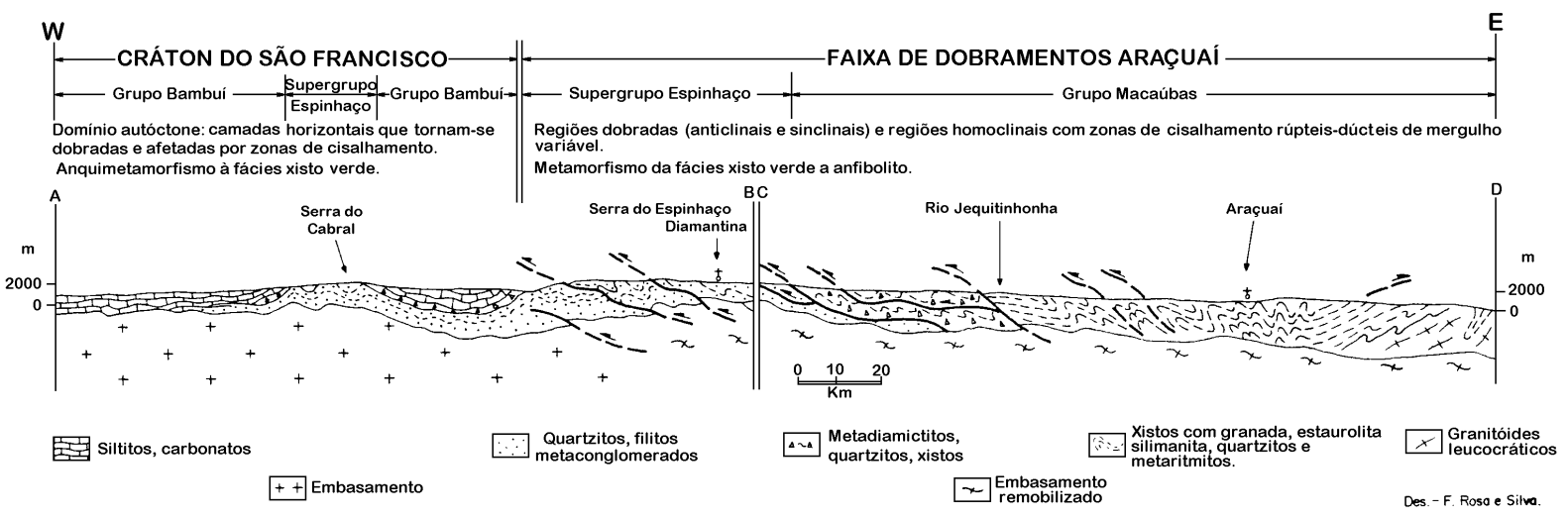

Figura 3: Seção estrutural esquemática do Cráton do São Francisco e da porção externa da Faixa Araçuaí (modificada de Uhlein et al., 1990). Localização da seção na figura 1.

Figure 3: Structural cross section of the São Francisco Craton and the external portion of the Araçuai fold belt (modified from Uhlein et al., 1990). For location see Fig. 1. 


\begin{tabular}{|c|c|}
\hline $\begin{array}{c}\text { DOMÍNIO DO CRÁTÓN DO } \\
\text { SÃO FRANCISCO } \\
\text { Gr. Bambuí } \\
\text { Sg. Espinhaço }\end{array}$ & $\begin{array}{c}\text { DOMÍNIO DA FAIXA ARAÇUAÍ } \\
\text { Gr. Macaúbas } \\
\text { Sg. Espinhaço }\end{array}$ \\
\hline $\begin{array}{c}\text { Dobras assimétricas de eixo norte-sul, abertas, e clivagens de crenulação } \\
\text { ou clivagem espaçada Sp+1. Lineação de crenulação N-S }\end{array}$ \\
$\begin{array}{c}\text { ardosiana ou xistosidade milonítica Sp (N-S; } 60 \text { a } 30^{\circ} \text { E). Lineação de estiramento E-W } \\
\text { (minerais e seixos elongados). Metamorfismo da fácies xisto verde a anfibolito. }\end{array}$ \\
- \\
Foliação Sp - 1 localmente visível \\
em micrólitons da foliação principal (Sp)
\end{tabular}

Figura 4: Estruturas relacionadas à tectônica de inversão do Ciclo Brasiliano na Serra do Espinhaço Meridional e zonas adjacentes. (Modificado de Uhlein et al, 1990; Uhlein, 1991 e Uhlein e Trompette, 1993). Figure 4: Structures related to the tectonic inversion of the Brasiliano Cycle in the southern Serra do Espinhaço and adjacent areas (modified from Uhlein et al., 1990; Uhlein, 1991; Uhlein \& Trompette, 1993).

e contituem importante feição tectônica da Cordilheira (Herrgesell \& Pflug 1986; Rolim 1992; Uhlein \& Trompette 1993; Silva \& Toledo 1993). Falhas de rasgamento, aproximadamente E-W, com deslocamento direcional e/ou vertical, completam o quadro estrutural da região.

O Supergrupo Espinhaço, considerado como embasamento das unidades neoproterozóicas (Grupo Macaúbas e Grupo Bambuí) experimentou levantamento generalizado e basculamentos localizados, quando da tectônica extensional responsável pela individualização da Bacia Araçuaí. O Supergrupo Espinhaço mostra a mesma estrutura (xistosidades $\mathrm{Sp}-1, \mathrm{Sp}$ e $\mathrm{Sp}+1$ ) que os grupos Macaúbas e Bambuí , idênticas dobras vergentes para W, e ainda, o mesmo e progressivo gradiente metamórfico que as unidades neoproterozóicas. Almeida Abreu (1993) e Almeida Abreu \& Pflug (1994) defendem que o Supergrupo Espinhaço seja um orógeno tectonizado no Ciclo Uruaçuano e reativado no Ciclo Brasiliano. Trabalhos de análise estrutural efetuados desde a segunda metade da década de 80 têm mostrado que o quadro estrutural do Supergrupo Espinhaço é o mesmo dos Grupos Bambuí e Macaúbas, o que significa dizer que o Supergrupo Espinhaço foi tectonizado e metamorfizado, apenas por ocasião da orogênese brasiliana.

\section{CONCLUSÕES}

A evolução geodinâmica dos terrenos a sudeste do Cráton do São Francisco mostra a superposição de dois rifteamentos: o primeiro no final do Paleoproterozóico e início do Mesoproterozóico e o segundo no limiar do Neoproterozóico. Uma forte tectônica compressiva (com dobramentos e metamorfismo progressivo) estabeleceu-se apenas no final do Ciclo Brasiliano (650-
550 m.a.). Inicialmente, desenvolveu-se um rifte continental (ensiálico), orientado segundo a direção norte-sul e preenchido pelos metassedimentos do Supergrupo Espinhaço. Iniciou-se a aproximadamente 1,7 b.a. com sedimentos continentais e vulcanismoplutonismo ácido-intermediário sub-alcalino. Evoluiu para uma sedimentação de ambiente marinho raso durante o Mesoproterozóico, em fase de subsidência térmica e flexural. No limiar do Neoproterozóico, o sistema Espinhaço foi reativado por um tectonismo extensional responsável pela individualização da bacia ou rifte Araçuaí e ocorreram intrusões de rochas básicas toleiíticas continentais (gabros e diabásios). A bacia Araçuaí é preenchida por sedimentos de retrabalhamento gravitacional (debris-flow e turbiditos) derivados da erosão do embasamento, Supergrupo Espinhaço e material glaciogênico, que caracterizam uma margem continental passiva. $\mathrm{Na}$ fase de subsidência térmica do rifte Araçuaí deposita-se o Grupo Bambuí. No final do Neoproterozóico, o sistema Espinhaço e a Bacia Araçuaí experimentam forte tectônica de inversão, em regime compressional, com dobras, zonas de cisalhamento, metamorfismo regional e espessamento litosférico. Individualizam-se as unidades estruturais do Cráton do São Francisco, Faixa Araçuaí e Faixa Paramirim.

\section{AGRADECIMENTOS}

Os autores são gratos à Comissão Organizadora do $8^{\circ}$ Simpósio de Geologia de Minas Gerais pelo honroso convite. Agradecem também às instituições de fomento à pesquisa como CNPq, CAPES, FAPESP e PRPqUFMG pelo apoio financeiro e a empresas como PETROBRÁS, CPRM, CVRD-DOCEGEO, e COMIG pelo apoio eventual e sempre necessário. O Prof. Dr. F. Renger fez a correção do abstract . 


\section{REFERÊNCIAS BIBLIOGRÁFICAS}

ALKMIM, F.F.; CHEMALE JR., F.; BACELLAR, L.A.P.; OLIVEIRA, J.; MAGALHÃES, P.M. - 1989 - Arcabouço estrutural da porção sul da Bacia do São Francisco. An. V Simp. Geol. Minas Gerais, SBG - Núcleo MG., Bol. n 10: 289-293.

ALKMIM, F.F.; BRITO NEVES, B.B. \& CASTRO ALVES, J.A. 1993 - Arcabouço tectônico do Cráton do São Francisco: uma revisão. In: O Cráton do São Francisco. DOMINGUEZ, J.M.L. \&MISI, A.(ed), SBG - Núcleo BA/SE: 45-62.

ALMEIDA, F.F.M. de - 1977 - O Cráton do São Francisco. Rev. Bras.Geoc. 7(4): 349-364.

ALMEIDA, F.F.M. de \& LITWINSKI, N. - 1984 - Província Mantiqueira, Setor Setentrional. In; ALMEIDA, F.F.M. de \& HASUI, Y. (coord.). O Pré-Cambriano do Brasil. Ed. Edgard Blücher Ltda., 282-307, São Paulo.

ALMEIDA ABREU, P.A. - 1993 - A evolução geodinâmica da Serra do Espinhaço Meridional, Minas Gerais, Brasil. Tese de Doutorado, Univ. Albert-Ludwig, Freiburg (Alemanha), 150 pg.

ALMEIDA ABREU,P.A.; FERNANDES,P.C.O.; KNAUER, L.G.;HARTMANN, M.B., DONATO, M.T.R. \& SCHORCHER, H.D.- 1986 - Elementos da zona de cisalhamento dúctil da borda oriental da Serra do Espinhaço, Minas Gerais. An. XXXIV Cong. Bras. Geol., vol. 3:1219-1231, Goiânia.

ALMEIDA ABREU, P. A.; KNAUER, L. G.; HARTMANN, M. B.; SANTOS, G. G. V dos; GUIMARÃES, M. L. V.; ABREU, F. R. de; SCHRANK, A. \& PFLUG, R. - 1989 - Estratigrafia, faciologia e tectônica do Supergrupo Espinhaço na região de Serro - Conceição do Mato Dentro, Minas Gerais, Brasil. Zbl. Geol. Paläont. 5/6, p. 857-873.

ALMEIDA ABREU, P.A. \& PFLUG, R. - 1994 - The geodynamic evolution of the southern Serra do Espinhaço, Minas Gerais, Brazil. Zbl. Geol. Paläont. Teil I (1/2) : 21-44.

ASSIS , L.C.\& MARINI, O.J. -1983- Contribuição à controvérsia da correlação Espinhaço - Minas. An. Simp. Geol Minas Gerais, SBG-Núcleo MG, Bol. n 3,361-375, Belo Horizonte.

BABINSKI, M. - 1993 - Idades isocrônicas $\mathrm{Pb} / \mathrm{Pb}$ e geoquímica isotópica de $\mathrm{Pb}$ das rochas carbonáticas do Grupo Bambuí, na porção sul da Bacia do São Francisco. Tese de Doutorado, Inst. Pesq. Energéticas e Nucleares - IPEN, 133 pg., São Paulo.

BERTHOLDO, A.L.; ALKMIM, F.F. \& TROUW, R.A.J. - 1993 O comportamento estrutural das coberturas meso e neoproterozóicas do Cráton do São Francisco nas Serras do Espinhaço Setentrional, Central e Palmas do Monte Alto (MGBA). An. II Simp. sobre o Cráton do São Francisco, SBG SGM, 205-207, Salvador.

BRITO NEVES, B.B. de; KAWASHITA,K.; CORDANI, U.G. \&DELHAL, J. - 1979 - A evolução geocronológica da Cordilheira do Espinhaço: dados novos e integração. Rev. Bras. Geoc. 9: 71-85.

CABY, R. \& ARTHAUD, M. - 1987 - Petrostructural evolution of the Lagoa Real subalkaline metaplutonic complex (Bahia, Brazil). Rev. Bras. Geoc. 17: 636.

CHANG, H.K.; MIRANDA, F.P.; MAGALHÃES, L. \& ALKMIM, F.F. - 1988 - Consideração sobre a evolução tectônica da Bacia do São Francisco. An. XXXV Congr. Bras. Geol. vol. 5: 2076 - 2090, Belém (PA).

CHEMALE JR., F.; ALKMIM, F.F. \& ENDO, I. - 1993 - Late Proterozoic tectonism in the interior of the São Francisco Craton. In: Gondwana Eight. Assembly, evolution and dispersal.FINDLAY, R.H.; UNRUG, R.; BANKS, M.R. \& VEEVERS, J.J.(ed.), Balkema, 29-41.

CORDANI, U.G.; S.S. IYER, TAYLOR, P.N.; KAWASHITA, K., SATO, K. \& McREATH, I. - $1992-\mathrm{Pb} / \mathrm{Pb}, \mathrm{Rb} / \mathrm{Sr}$ and $\mathrm{K} / \mathrm{Ar}$ systematics of the Lagoa Real uranium province (south-central Bahia, Brazil) and the Espinhaço Cycle (c.a. 1,5 - 1,0 Ga). Journ. of South Amer. Earth Sciences 5 (1): 33-46.

CHIAVEGATTO, J.R.S.- 1992- Análise estratigráfica das sequências tempestíticas da Formação Três Marias (Prot. Superior), na porção meridional do Craton do São Francisco. Tese de Mestrado, UFOP, 216 pg.

COSTA, L.A.M. \& INDA, H.A.V. - 1982 - O Aulacógeno do Espinhaço. Ciências da Terra, 2: 13-18.

COSTA,M.T. \& BRANCO, J.J.R.- 1961- Roteiro para a excursão Belo Horizonte -Brasília. Contribuição ao XIV Congr. Bras.
Geol., Public. 15, Inst. Pesq. Radioativas: 9-25 pg.

D'AGRELLA F., M.S.; PACCA, I.G.; RENNE, P.R.; ONSTOTT; T.C.; TEIXEIRA, W. - 1990 - Paleomagnetism of Middle Proterozoic(1,01 to 1,08 Ga) Mafic Dikes in SE Bahia State, São Francisco Cráton, Brazil. Earth Plan. Sci. Letl., 101 332348.

DANDERFER FILHO, A.; LAGOEIRO, L.E. \& ALKMIM, F.F. 1993 - O sistema de dobramentos e empurrões da Chapada Diamantina (BA): registro da inversão do aulacógeno do Espinhaço no decorrer do evento Brasiliano. An. II Simp. sobre o Cráton do São Francisco, SBG - SGM, 197-199, Salvador.

DARDENNE, M.A. - 1981 - Os Grupos Paranoá e Bambuí na Faixa Dobrada Brasília. An. I Simp. sobre o Cráton do São Francisco e suas faixas marginais. SBG - Núcleo BA, CPM/SME: 140157.

DOMINGUEZ, J.M.L. - 1993 - As coberturas do Cráton do São Francisco : uma abordagem do ponto de vista da análise de bacias. In: O Cráton do São Francisco. DOMINGUEZ, J.M.L. \& MISI, A. (ed) SBG/SGM. 137-160.

DOSSIN,T.M.- 1985- Geologia e geoquímica das formações ferríferas da Serra da Serpentina, Conceição do Mato DentroMG. Tese de Mestrado, UnB, 140 pg.

DOSSIN, I.A., GARCIA, A.J.V., UHLEIN, A.; DARDENNE, M.A. \& DOSSIN, T.M. - 1987 - Fácies eólico na Formação Galho do Miguel, Supergrupo Espinhaço (MG). An. Simp. sobre Sist. Deposicionais no Pré-Cambriano, SBG - Núcleo MG, Bol. n6: 85-96, Ouro Preto.

DOSSIN, I.A.; DOSSIN , T.M. \& CHAVES, M.L.S.C. - 1990 Compartimentação estratigráfica do Supergrupo Espinhaço em Minas Gerais - Os Grupos Diamantina e Conselheiro Mata. Rev. Bras. Geoc. 20: 178-186.

DOSSIN, I.A.; DOSSIN, T.M.; CHARVET, J. \& CHEMALE JR., F. - 1992 - Tectonique du Protérozoïque Supérieur au sud-est du Cráton São Francisco (Minas Gerais, Brésil). C.R. Acad. Sci. Paris, 315: 629-636, Paris

DOSSIN, I.A. \& CHARVET, J. - 1993- Mise en évidence d'une tectonique ante-Brasiliano dans la région de la Serra Negra, bordure SE du Craton São Francisco (Brésil). C.R.Acad. Sci. Paris,317-II:819-826.

DOSSIN, I.A.; DOSSIN, T.M.; CHARVET, J.; COCHERIE, A \& ROSSI, P. - 1993a - Single-zircon dating by stepwise $\mathrm{Pb}$ evaporation of Middle Proterozoic magmatism in the Espinhaço Range, Southeastern São Francisco Cráton (Minas Gerais, Brazil). An. II Simp. sobre o Cráton do São Francisco, SBG SGM, 39-42, Salvador

DOSSIN, T.M.; DOSSIN, I.A.; CHARVET, J.; POUCLET, A.; LAPIERRE, H. - 1993b - Late Proterozoic mafic dykes swarm from the Espinhaço Range (Minas Gerais, Brazil): geochemistry and tectonical setting. An . II Simp. sobre o Cráton do São Francisco, SBG - SGM, 128-130, Salvador.

DUSSIN, I.A. - 1994 - Evolution structurale de la region de L'Espinhaço Meridional, bordure sud-est du Cráton São Francisco, Brésil. Tectoniques superposées au Protérozoïque. Tese de Doutorado, Univ. d'Orléans (França), 200 pg.

DUSSIN, T.M.- 1994 - Associations volcano-plutoniques de l'Espinhaço Meridional (SE-Brésil). Un exemple d'evolution de la croûte protérozoïque. Tese de Doutorado, Univ. d'Orléans (França), 181 pg.

FLEISCHER, R. - 1993 - Um modelo rift para os depósitos sedimentares de diamante do Brasil. An. Simp. Bras. Geol. do Diamante. UFMT, Publ. Esp. 2: 165-197, Cuiabá (MT).

FOGAÇA, A.C.C.; ALMEIDA ABREU, P.A. \& SCHORSCHER, H.D.-1984- Estratigrafia da sequência supracrustal arqueana na porção mediana central da Serra do Espinhaço Meridional. An XXXIII Congr. Bras. Geol., vol. 6: 2654-2667, Rio de Janeiro.

FUCK, R.A.- 1991 - Aprovada nova escala de tempo para o PréCambriano. Rev. Bras. Geoc. 21 (2): 182-183.

GARCIA, A.J.V. \& UHLEIN, A. - 1987 - Sistemas Deposicionais do Supergrupo Espinhaço na região de Diamantina (MG). An. Simp. sobre Sist. Deposicionais no Pré-Cambriano, SBG Núcleo MG, Bol. nº: 113-136, Ouro Preto.

HERRGESELL, G. - 1985 - Uma margem continental proterozóica na Serra do Cipó Setentrional (Serra do Espinhaço Meridional). Anais III Simp. Geol. Minas Gerais, SBG - Núcleo MG, Bol. $\mathrm{n}^{\circ}$ 5: 1-15, Belo Horizonte.

HERRGESELL, G. \& PFLUG, R. - 1986 - The thrust belt of the Southern Serra do Espinhaço, Minas Gerais, Brazil. Zbl. Geol. 
Paläont. Teil I, (9/10): 1405-1414.

HOPPE, A. \& OTTO, J.- 1982 - Vulcanic rocks of the Espinhaço Supergroup (Proterozoic I), Eastern Brazil. V Cong. Latinoamericano de Geologia, IV: 125-135, Argentina.

INDA, H.A.V. \& BARBOSA, J.F. - 1978 - Texto explicativo para o Mapa Geológico do Estado da Bahia, escala 1:1000.000. CPM - SME/CBPM, $137 \mathrm{pg}$

JARDIM DE SÁ, E.F.; BARTELS, R.L.; BRITO NEVES, B.B. de \& McREATH, I. - 1976 - Geocronologia e o modelo tectonomagmático da Chapada Diamantina e Espinhaço Setentrional, Bahia. An. XXIX Congr. Bras. Geol. 4: 205-228, Ouro Preto.

KARFUNKEL, J. \& KARFUNKEL, B. - 1976 - Estudos petrofaciológicos do Grupo Macaúbas na porção mediana da Serra do Espinhaço, Minas Gerais. XXIX Congr. Bras. Geol. vol.2: 179-188, Ouro Preto.

KARFUNKEL, J. \& HOPPE, A. - 1988 - Late Proterozoic glaciation in Central Eastern Brazil: synthesis and model. Paleogr., Paleocl., Paleoecol. 65: 1-21.

KNAUER, L.G. - 1990 - Evolução geológica do Pré-Cambriano da porção centro-leste da Serra do Espinhaço Meridional e metalogênese associada. Tese de Mestrado. Unicamp, $230 \mathrm{pg}$.

KNAUER, L.G. \& SCHRANK, A. - 1993 - A origem dos filitos hematíticos da Serra do Espinhaço Meridional, Minas Gerais. Geonomos vol. 1: 33-38 pg.

LITWINSKI, N. - 1985 - Evolução tectono-termal da região nordeste de Minas Gerais e Sul da Bahia. Tese de Doutoramento, USP, $207 \mathrm{pg}$.

MACHADO, N.; SCHRANK, A.; ABREU, F.R.; KNAUER, L.G.; ALMEIDA ABREU, P.A. - 1989 - Resultados preliminares da geocronologia U-Pb na Serra do Espinhaço Meridional. Anais V Simp. Geol. Minas Gerais, SBG - Núcleo MG., Bol. n 10 : 171-174, Belo Horizonte.

MARSHAK, S. \& ALKMIM, F.F. - 1989 - Proterozoic contraction/ extension tectonics of the Southern São Francisco Region, Minas Gerais, Brazil. Tectonics, vol. 8 (3): 555-571.

MARTINS NETO, M.A.; ALMEIDA ABREU, P.A. \& BRICHTA, A. - 1988 - Sistemas Deposicionais das Formações São João da Chapada e Sopa Brumadinho (Supergrupo Espinhaço) na região de Diamantina/Costa Sena (MG). Anais XXXV Congr. Bras.Geol. vol 2: 633 - 647, Belém (PA).

MARTINS NETO, M.A. - 1993 - The sedimentary evolution of a Proterozoic rift basin: the basal Espinhaço Supergroup, Southern Serra do Espinhaço, Minas Gerais, Brazil. Tese de Doutoramento, Univ. de Freiburg (Alemanha), 155 pg.

MENEZES FILHO, N.R. - 1980 - Sequência vulcano/ vulcanoclástica da Serra do Riacho Seco (Monte Azul, MG) Supergrupo Espinhaço. An. XXXI Congr. Bras. Geol., vol.4: 2104-2118, Camboriú.

PEDROSA SOARES, A.C.; MONTEIRO, R.B.P.; NOCE, C.M.; FREITAS- SILVA, F.H.; OLIVEIRA, M.J.R. \& SCHETTINO, A. - 1990 - Caracterização de uma sequência vulcanosedimentar distal na Faixa Araçuaí (MG): bacia oceânica restrita? XXXVI Congr. Bras. Geol., Bol. de Resumos, Natal(RN).

PEDROSA SOARES, A.C.; GROSSI SAD, J.H. \& VIDAL, Ph. 1993- Evidences of a constructive margin in the Sanfranciscan Plate (Araçuaí Belt, MG): a geochemical evaluation of metabasic rocks. An. II Simp. sobre o Cráton do São Francisco, SBG - SGM, 131-133, Salvador.

PEDROSA SOARES, A.C.; NOCE, C.M.; VIDAL, Ph.; MONTEIRO, R.L.B.P. \& LEONARDOS, O.H. - 1992 Toward a new tectonic model for the Late Proterozoic Araçuaí (SE Brazil) - West Congolian (SW Africa) Belt. J. South American Earth Sciences, 6 (1/2): 33-47.

PFLUG, R. - 1965 - A geologia da parte meridional da Serra do Espinhaço e zonas adjacentes, Minas Gerais. Bol. 226, Div. Geol. Miner., DNPM, Rio de Janeiro.

PFLUG, R. - 1968 - Observações sobre a estratigrafia da Série Minas na região de Diamantina, Minas Gerais. Not. Prelim. e Estudos $n^{\circ}$ 142, Div. Geol. Min., DNPM, Rio de Janeiro.

PFLUG, R.; HOPPE, A. \& BRICHTA, A. - 1980 - Paleogeografia do Pré-Cambriano na Serra do Espinhaço, Minas Gerais, Brasil. In: ZEIL, W. (ed.). Nuevos Resultados Geocientíficos Alemanhia em Latinoamerica, 33-43, Boppard.

RENGER, F.-1970- Fazies und Magmatismus der Minas-Serie in der Südlichen Serra do Espinhaço, Minas Gerais, Brasilien. Geol. Rundschau, 59:1253-1292.
RENGER, F.-1972- As rochas ultrabásicas da Serra do Espinhaço, Minas Gerais. Rev. Bras. Geoc. 2: 151-160.

ROLIM, V.K. -1992- Uma interpretação das estruturas tectônicas do Supergrupo Espinhaço, baseada na geometria dos falhamentos de empurrão. An 6 Simp. Geol. Minas Gerais, Rev. Esc. Minas 45 (1 e 2): 75-77, Ouro Preto.

SIGA JR., O. - 1986 - A evolução geotectônica da porção nordeste de Minas Gerais, com base em interpretações geocronológicas. Tese de Mestrado, USP, $140 \mathrm{pg}$.

SIGA, JR., O.; CORDANI, U.G.; BASEI, M.A.S.; TEIXEIRA, W.; KAWASHITA, K. \& VAN SCHMUS, W.R. - 1987 Contribuição ao estudo geológico e geocronológico da porção nordeste de Minas Gerais. An. $4^{\circ}$ Simp. Geol. Minas Gerais, SBG - Núcleo MG., Bol. n 7: 29-44, Belo Horizonte.

SCHOBBENHAUS, C.; CAMPOS, D.A.; DERZE, G.R. \& ASMUS, H.E. - 1981 - Mapa geológico do Brasil e da Área Oceânica Adjacente Incluindo Depósitos Minerais, esc. 1: 2.500.000, MME - DNPM.

SCHOBBENHAUS, C. - 1993 - O Proterozóico Médio no Brasil com ênfase à região Centro-Leste: uma revisão. Tese de Doutorado, Univ. Albert-Ludwig, Freiburg (Alemanha), 166 pg.

SCHÖLL, W.U. \& FOGAÇA, A.C.C. - 1979 - Estratigrafia da Serra do Espinhaço na região de Diamantina. $1^{\circ}$ Simp.Geol.Minas Gerais, SBG- Núcleo MG, Bol. ${ }^{\circ} 1,55-73$, Diamantina.

SILVA, A.M.; KUYUMJIAN, R. \& CHEMALE JR., F. - 1992 Rochas básicas no Quadrilátero Ferrífero e Espinhaço Meridional: Estudos preliminares. An. 6 Simp. Geol. Minas Gerais - Rev. Esc. Minas, 45 (1/2): 60-62, SBG - SICEG CPRM, Ouro Preto

SILVA, R.R. - 1993 - Sequências estratigráficas da fase rift do Supergrupo Espinhaço, Diamantina, MG. An. Simp. Craton do São Francisco, SBG-SGM, 154-157, Salvador.

SILVA, R.R. \& TOLEDO, C.L.B.-1993- A Proterozoic duplex thrust system in the Southern Serra do Espinhaço, Minas Gerais, Brazil. Zbl. Geol. Paläont, Teil I,H.1/2:55-66.

TROMPETTE, R.; UHLEIN, A.; EGYDIO-SILVA, M. \& KARMANN, I. - 1992 - The brasiliano São Francisco Cráton revisited (Central Brazil). J. South Am. Earth Sciences 6 (1/2): 49-57.

TROMPETTE, R. - 1994 - Geology of Western Gondwana (2000$500 \mathrm{Ma})$. Pan-African-Brasiliano Aggregation of South America and Africa. Balkema, $352 \mathrm{pg}$.

UHLEIN,A.- 1982- Geologia e mineralizações de cromita e itabiritos da região de Serro- MG. Tese de Mestrado, UnB, 189 pg.

UHLEIN, A.; ASSIS, L.C. \& DARDENNE,M.A. - 1983- As mineralizações de ouro e cromita da Sequência VulcanoSedimentar de Serro. An. 2 Simp. Geol. Minas Gerais, SBGNúcleo MG, Bol. $n^{\circ}$ 3:306-320, Belo Horizonte.

UHLEIN, A. \& DARDENNE, M.A.- 1984- Estratigrafia e tectônica da região de Serro, borda leste da Serra do Espinhaço Meridional. An. XXXIII Cong. Bras. Geol., vol.V:2289-2301, Rio de Janeiro.

UHLEIN, A.; TROMPETTE. R.; EGYDIO-SILVA, M. - 1986 Estruturação tectônica do Supergrupo Espinhaço na região de Diamantina (MG). Rev. Bras. Geoc. 16(2): 212-216.

UHLEIN, A., EGYDIO-SILVA, M.; TROMPETTE, R. - 1990 - A faixa de dobramentos Araçuaí no Estado de Minas Gerais; uma cadeia monocíclica de idade brasiliana. An. XXXVI Congr. Bras. Geol. vol.6: 2576-2588, Natal(RN).

UHLEIN, A. - 1991 - Transição cráton-faixa dobrada: exemplo do Cráton do São Francisco e da Faixa Araçuaí (Ciclo Brasiliano) no Estado de Minas Gerais. Aspectos estratigráficos e estruturais. Tese de Doutorado. USP, 295 pg.

UHLEIN, A. \& TROMPETTE, R. - 1992 - A evolução de um rift intracontinental para uma margem continental passiva: o exemplo da faixa de dobramentos Araçuaí (MG). An. XXXVII Congr. Bras. Geol. vol. 1: 293-295, São Paulo.

UHLEIN, A. \& TROMPETTE, R. - 1993 - Cisalhamento dúctil, dobras com eixo paralelo à lineação de estiramento e a estrutura da faixa Araçuaí (MG). Geociências 12 (1): 71-87, São Paulo.

UHLEIN, A.; TROMPETTE, R. \& ALVARENGA, C.J.S. de - 1994 - Late Proterozoic gravitational sedimentation on a continental margin under glacial influence: the Jequitaí - Macaúbas sequence (Minas Gerais, Brazil). 14 th Intern. Sed. Congress, Abstracts, G85-86, Recife. 
